Hepatica Rosea; Common Dark Polyanthus ; Snowdrops; Tberis Ciliata; Anemone Hortensis, and a variety introduced from the Pyrenees; Chrysenthemum (small double yellow); Double White and Double Lilao Primroses; Cynoglossum Omphalodes.

Grownia agamst Watus. Common China Rose ; Common Red Rose; Veronica Speciosa; Veronica Cindciana; Clyanthus Punicea; Pyrus Japonica; Coronilla Glanca; Fuchsia Serratifolia ; Scarlet Geranium (Smith's Emperor); Red Salvia.

February. Camelia Japonica (single red, double red, variegated, white, and other varieties); Erica (dwarf pink, Mediterranean, and Arborea Alba); Petus Porum; Coronilla Glauca; Berberis Equifolia; Laurustinus (shining leaved and common); Ulex (double yellow furze); Polygala Latifolia; Rosmarinus Officinalis; Magnolia Conspicus; the Almond Tree; Standard Plum Trees; Hepatica (pink and blue); White and lilac Madagascar Primula (Rosea and Alba); Violets (Russian, Neapolitan, and French tree); Narcissus (bicolor and odorus); Pseudo-Narcissns; Hyacinthus (common single, of various colours); Scarlet Star Anemones; Polyanthus, of various colours; Auricula, ditto; Iberis Perennis; Crocus, of various colours; Arabis Alpina; Nemophylla Insignis Alba; Vinca, major and minor; Cheiranthus (double yellow); Cheiranthus Maritimus; Muscari Racemosum; Arnopogon; Mesembryanthemum (bicolor and a pale pink, and small purple variety); Genista Hybrida; Rhododendron Arborea Hybrida.

Aaninst Warrs. Veronica Speciosa; Common China Rose; Peseh, Nectarine, and Apricot trees.

\title{
ON INFLAMMATION OF THE VAGINA.
}

By T. SNOW BECK, M.D.Lond., F.R.S., F.R.C.S.; Physician to the Farringdon General Dispensary and Lying-in Charity; Secretary of the London Medical Society of Observation, etc.

[Read before the Medical Society of London.]

THE large tract of mucous membrane, extending from the orifice of the vagina to the orifice of the uterus, is obnoxious to various diseases; and unquestionably the affection most frequently met with in practice is inflammation. The inflammation may be partial, or extend over the whole surface; it may be acute or chronic; it may be limited to the vagina, properly so called, or it may extend upwards into the membrane lining the uterus, and finally involve the proper structure of this orgun ; or extend downwards, and implicate the mucous membrane of the vulva; it may also extend beyond the substance of the membrane, attack the cellular tissue which surrounds it, and cause the formation of abscesses in this situation; or the erectile tissue which partially surrounds the vagina, may, together with the large and numerous veins, become implicated in the morbid action, and constitute a most distressing affection. Each of these variations in the character and extent of the inflammation causes a difference in the symptoms, and requires a modification in the treatment; but it is only inflammation of the vagina, considered in a general manner, and without reference to particular modifications, that can be considered within the limits of this paper.

Srmptoms. When consulted by a patient labouring under an affection of this kind, it is rare, except in severe or acute cases, that our attention is directed to the seat of the disease. She frequentls com- 
plains of a dull heavy pain across the forehead, general weakness, pain in the back, in the stomach, and in the calves of the legs, or of some condition of the general health, which has been induced by the long continuance of the local disease. It may be that a vaginal discharge is stated to exist, and that the menstrual periods occur every two or three weeks, and continue longer than usual; but the distinctive symptoms are, as a rule, only admitted by the patient when questioned on the subject. These are-a fulness, and throbbing in the vagina; pains shooting up the canal into the abdomen; tenderness on sitting, especially on a soft seat; great pain on the passing of the fæces; a sensation of bearing down, or as if something would pass from the vagina; with frequent desire to pass the urine, and occasional retention of that fluid. But it may be well to consider these symptoms rather more in detail.

The pains which are present are seated in the sacral region, extending round the hips into the perinæum, down the posterior and outside of the thighs, and in the calves of the legs. They are, in fact, in the course of the nerves derived from the sacral plexus, from which the vaginal nerves are likewise derived, and hence, no doubt, the reason why pains present in affections of the vagina are reflected along the nerves furnished by the sacral plexus. In respect to diagnosis, it is important to notice the situation of these pains, for, as I have elsewhere shown, affections of the uterus itself cause pains in the lumbar and dorsal regions, and in the nerves derived from these parts, and not in the sacral portion of the spinal column. The pain at the lower part of the stomach, or rather, deep in the hypogastric region, is likewise strongly indicative of a vaginal affection, inasmuch as pains reflected from the uterus are seated, not in the hypogastric region, but in the sides of the abdomen, above the inguinal region. The local fulness and throbbing, together with tenderness on pressure, either on sitting on a soft scat, or during the passage of the fæces, are obviously referrible to the local disease; but the bearing down, which is also present, and which has been usually attributed to an affection of the uterus, is deserving of note. From my own observations, I do not hesitate to refer this symptom to disease of the vagina, the mucous membrane of which becomes thickened and swollen, and hence causes the feeling of a substance being present, having a tendency to pass away. However, it no doubt frequently exists when the nterus is the seat of disease ; but in these cases the ragina also is implicated; and even when no affection of the vagina is present, it will be found that the symptom is occasioned by the pressure of the descending uterus upon this canal, and therefore is still derived from the vaginal complication. The frequent desire to pass the urine, and the occasional retention of this fluid, appears to be the consequence of irritation, reflected from the vaginal nerves to those distributed to the bladder. It does not appear probable that it arises from the extension of the inflammation to this viscus, for that would involve a greater degree of morbid action than is usually present; nor can it be caused by any unhealthy state of the urine, for this fluid, when tested, is not found, even in most marked cases, to be altered from the healthy condition.

In inflammation of the vagina, some discharge is usually present, whether this be purulent, muco-purulent, or white mucous; but it may be entirely absent. Frequently in acute inflammation there is no dis- 
charge; and often, when an acute attack is engrafted upon chronic inflammation, the raginal discharge, previously present, ceases; and when repeated a few times, will cause the patient to remark, that " she is always easier when the discharge comes freely away." It will not, I think, admit of a doubt, that the state of the membrane which gives rise to these various conditions of the discharge must vary, according to the presence or absence, or the character of the discharge ; yet, for the present, I must pass over this point of the inquiry. It is, however, worthy of note, that in affections attended with vaginal discharge, or, as it is termed, leucorrhoea, this discharge is the product of the vagina, and not of the uterus, as has been hastily supposed.

The ancient division of leucorrhœea, into vaginal and uterine, appears to have been made when the diagnosis between these two diseases was as yet very imperfect, and is now retained by some authors, on the plea that purulent fluid sometimes is seen to escape from the orifice of the uterus during an examination with the speculum. That purulent fluid and white of egg mucus does escape from the cavity of the uterus is certain, but practically we must bear in mind, that the amount is too small to escape externally, and constitute what patients call "a discharge". Another important practical condition attending inflammations of the vagina, is the disturbance which they induce in the menstrual function. Soon after the appearance of the inflammation, the catamenia are observed to appear a few days within the proper period of their recurrence, to continue longer than usual, and to be greater in quantity, whilst the purulent or muco-purulent discharge again occurs in the interval. These alterations gradually increase in degree, until the menstrual discharge appears every fortnight, or oftener, continues seven or eight days, and consists of a copious flow of bright florid fluid, often mixed with coagula of blood. In some cases, I have known a red discharge, depending on inflammation of the vagina, to continue for sixweeks without intermission, and to withstand the effect of various astringent remedies, until the inflammation was subdued by the free application of leeches. Nor was this discharge of trifling amount, for both from its quantity and the effect it produced on the constitution, it might strictly be termed menorrhagia.

A curious physiological question arises out of this clinical observation of the effect of vaginal inflammation upon the catamenial functions;viz., by what influence is this effect produced? I must, however, leave the solution of this question to those who have accepted the imaginary theory of the influence of ovarian excitation upon this function. For myself, the phenomenon in question appears an insurmountable obstacle to this supposed influence. It might be said that this red discharge was not the appearance of the menstrual function, but only a flow which simulated it ; but if such a line of argument were adopted, I am unable to perceive how it could be supported. The discharge is not a vicarious flow, varying in recurrence, in duration, or in amount, but appears regularly in respect of each of these characters, has gradually superseded the regular monthly periods, and presents no appreciable difference from the usual catamenial flow.

The constitutional states which are cansed by these affections vary much according to the original constitution of the patient, the hygienic conditions in which she is placed, and the duration of the discase. In 
severe cases, the continued pain which is endured night and day, the inability to find a resting place when in bed, and the frequent recurrence of increased pain at the catamenial periods, now recurring very frequently, quickly produce a state of debility and nervousness which, at times, becomes excessive. The constitutional derangement is further aggravated by the actual loss of blood, too great for the system to bear, and by disorder of the bowels; yet, as a rule, the appetite is not much impaired. It is also a curious observation, that in these affections pain across the forehead is almost invariably present.

On a local examination, the vagina presents the characters of a mucous membrane suffering from various conditions of inflammation. When examined with the finger, the orifice and the cavity of the vagina may be small, the membrane hot, and exceedingly tender, though neither swollen nor lubricated by any fluid, whilst the arteries are felt to beat bencath the finger with increased force. On other occasions, in addition to the heat and tenderness, the membrane is much swollen, lying in large smooth folds, or, is much corrugated. Frequently a portion of it projects, like a fringe surrounding the orifice, into the vulva, being acutely tender, and causing great difficulty in progression. In more chronic cases, the vagina becomes ample, and the membrane evidently thickened; it is tender, and covered with a copious secretion, and the increased pulsation of the arteries is still perceptible; on other occasions, the membrane is not only thickened, but coriaceous to the feel, communicating to the finger rather the impression of soft skin than that of mucous membrane. Viewed by the speculum, the membrane presents various shades of red, from an increase in the natural colour of the part to bright florid, or livid mahogany red; the colour may likewise be either uniform or mottled in various degrees. When it is thickened and coriaceous, the colour is even paler than natural, and has the appearance termed "mammillation". "This mammillated condition of the vagina frequently ceases abruptly at the orifice of the uterus, and has been mistaken for the margin of an ulcer, supposed to occupy the " orifice of the uterus".

In regard to the existence of ulceration of the uterus, there can be no doubt that it is a rare, instead of a frequent disease, and that the term has been applied to various morbid conditions, which are essentially different from ulceration. But in this particular instance some excuse may be offered, inasmuch as it requires a somewhat careful examination of the subject, in order to appreciate the morbid alterations. That this is no imaginary case, may be illustrated by an example which occurred to me so recently as the 9th of March 1852.

CAse. A girl, aged 16, rather tall, with fair skin, of good conformation, and moderately stout, entered the London Fever Hospital, suffering from an acute discase in the head. After a few weeks, she died; and, being present at the post-mortem examination, I had an opportunity of examining the condition of the uterine organs. The body of the uterus was rather low in the pelvis, as viewed from above, inclined to the left side, swollen, rounded in appearance, and of a dull, rather deep red colour, which depended on the minute injection with blood of the vessels of the organ. The Fallopian tubes were similarly injected, but of a deeper red colour, especially at their fimbriated extremities; the pelvic veins were also much loaded with blood; the ovaries, about 
the natural size, were pale, and strongly contrasted in colour with the injected tissues in the neighbourhood. To the feel, the body of the uterus was uniformly soft and elastic, and antiflexed near or at the junction of the cervix with the body. The orifice of the vagina was large, and obstructed by folds of thickened mucous membrane; whilst the cavity of this passage was enlarged, the mucous membrane thickened, coriaceous to the feel, lubricated with secretion, and lying in loose folds. The lips of the uterus were smooth, the orifice not notably altered from the healthy state, the neck somewhat enlarged, and the antiflexion of the body, previously noticed, distinctly perceived. On the removal of the organs from the body, the thickened mammillated condition of the vaginal mucous membrane was recognised; and this ceased abruptly by a defined margin at the orifice of the uterus, within which the tissues appeared red and swollen. So peculiar were these appearances, that I was unable to say whether they were only due to inflammation, or whether some further morbid change had not taken place. And in spite of a previous opinion that there was as yet no case on record, which could be trusted, of ulceration occurring at the orifice of a virgin uterus, it appeared, at first sight, that this lesion existed in the present case. My friend Dr. Sankey, who, from his extensive experience at the Fever Hospital, is well versed in pathological appearances, was equally unable to solve the doubt; whilst Dr. Tweedie, who saw it for an instant, jokingly charged me with making the appearances with the scalpel. However, on opening the cavities of this organ, this appearance was seen to depend on a fringe of membrane, about one-sixteenth of an inch in depth, which bordered the defined margin of the mamillated vaginal mucous membrane; and beyond this the lining membrane of the cervix uteri was injected, but otherwise healthy. To test more accurately the presence or absence of excoriation, the edge of a clean scalpel, not previously used, was drawn over the surface of the small fringe of membrane, and an abundance of epithelium covering the part, as shown by the microscope, obtained. From the lining membrane of the neck of the uterus, the epithelium was more difficult to separate, in consequence of not being loosened by the previous inflammatory action; for it would appear that when inflammation is carried to a certain point, but short of that stage where this covering is shed, and excoriation produced, the epithelium is more readily detached by the edge of a scalpel, than in an otherwise healthy membrane. The facts of this case are very significant at the present time; for, had this girl been treated by the use of the speculum, (and I have since understood she had been,) the real disease-chronic inflammation and thickening of the vaginal mucous membrane-would have been overlooked, and the part-the orifice of the uterus-which was little changed from the healthy condition, considered the seat of an imaginary disease. It also shows that we cannot correctly estimate the character and extent of disease in the uterus, by looking at the orifice through the medium of the speculum. The parts described have been preserved; and although the appearances are much altered, by immersion in salt and water for upwards of a month, yet even in this state, the preparation may be subservient to correct some mistakes as to the pathological appearances in these diseases. I allude to the statement, that the distinctive sharacters of 
ulceration quickly pass away after the examination of the body; or, that the presence of this lesion can only be determined, with certainty, by clinical examination of the living subject. As shown in this instance, the congestion of the blood-vessels, and the red colour indicative of inflammation, quickly pass away; but when any lesion of the tissues has taken place, this can be as distinctly recognised after the lapse of some time, as on the day of the first examination; for it so happened that a minute speck of superficial ulceration, one-twelfth of an inch in length, existed on one of the lips of the uterus, and this lesion is still visible. The mammillated condition of the raginal mucous membrane, although much changed, also retains its distinctive characters; whilst the seat of the fringe of swollen mombrane is marked by a narrow dark line.

Treatment. The ultimate object in the cultivation of the knowledge and diagnosis of diseases is, without doubt, that we may arrive at the means by which they are most easily and most certainly relieved. And in treating this part of the subject, I will consider inflammations of the vagina as they occur in the acute stage, in the chronic stage, and when thickening or ulceration of the tissues has been produced.

In the acute stage, when the membrane is swollen, intensely tender, with or without discharge, and the arteries of the part beat with a force and character which closely simulates the state of the vessels in a finger during the formation of a whitlow, the abstraction of blood appears clearly indicated. Except, however, in those plethoric habits where it is necessary to relieve the general tension of the system, general bleeding is rarely, if ever, required; but the local abstraction of blood, by leeches applied to the perinæum or vulva, is of great service. The vessels of the part, as well as the large plexus of the pelvic veins, are more effectually relieved by this, than by any other means; and the bleeding may be further encouraged by fomentations, or, what is better, by the use of bran poultices. The poultices, again, should be ample, larger than sufficient to cover the whole of the perinæum, and the hips should be surrounded by a blanket, folded in a triangular form, which is passed round the pelvis, and one end brought up between the thighs, after the manner of applying a baby's napkin. This admits of a local application of heat and moisture, by the frequent changing of the poultices, for a greater length of time, and more effectually, than by other means; whilst the blanket not only converts the application into a hip-bath, by retaining the heat and moisture around the hips, but prevents the bed becoming damp, and consequently admits of the whole being removed at any period. The administration of aperients is important, in order to remove any obstruction the loaded condition of the intestine might offer to the return of the blood; yet we ought not to forget that the bowels are frequently much loaded, are very obstinate to move, and that, when they are so, great pain is produced by the passage of the fæces, which for a time aggravates the disease, and often draws complaints from the patient that the remedies make her worse. It is, however, important to remove all obstruction, especially in the large intestines, and sometimes even an enema is required, the administration of which will likewise give much pain. The liquor potassæe, and the acetate of potash, are sometimes of much service; but their lengthened administration weakens the general health. Fre- 
quently there are difficulties to be encountered, in severe cases, which experience alone, it appears, could have taught. The pain is so great in the sacral region, that the patient is unable to find a resting-place in bed, and seeks relief by sitting on a hard seat, with the body bent forwards, and the elbows resting on the knees. If during the night she endeavours to obtain a little repose, no sooner is she lost in sleep, than the mind wanders in some frightful dream, some movement of the body is made to respond to the imaginary incidents, and she is again awoke by the pain which these movements produce. Should the attack occur during the winter, the patient, unable to sleep or find a resting-place, seeks relief by sitting up in bed covercd with shawls, cloaks, etc., when, after a time, the head becomes very painful and giddy, and she is again compelled to resume the recumbent posture, "shivering with cold". It is requisite to be acquainted with these circumstances, in order that the attention may not be drawn from the cause of the symptoms, and that we may steadily pursue the means to relieve the local inflammation; paying attention, at the same time, to the constitutional disturbance which is incurred. The use of narcotics generally affords temporary relief; and perhaps the combination of henbane and morphia quiets the system as well, and affects the head as little, as any other. Each case further requires some modification of the treatment, in order to suit the constitution of the patient, and the general condition of health in which she may have been, at the time of the attack. Further than washing the external parts with warm water, the vagina is too tender to admit of the employment of blisters. After a time, the acute symptoms pass away, the membrane secretes a muco-purulent or purulent discharge, the chronic stage of the affection is established, and we now have one of those diseases to which the name leucorrhœa has been applied.

In the chronic stage, it is not requisite to confine the patient to her bed, nor to prevent her attending to her household duties; yet long walks ought to be avoided. The diet may be more generous; and strict attention must be paid to the condition of the bowels, which usually become disordered, by reason of the patient delaying their action as long as possible, from a dread of the pain it creates. An aloetic digestive pill, taken before dinner, generally suffices to ensure their regular action; and when anæmia is present, one or two grains of the sulphate of iron is an excellent addition. It is in this stage that the balsam of copaiba, either in the form of a mixture or as drops, is of great service; as also the powdered cubebs, given twice or thrice a day, and combined or not with the carbonate of iron, according to the special indications of the case. It is now also, that the tincture of cantharides has been found by some to be so serviceable. During the flow of the menses, which recur at short intervals, with an increase in the quantity, these medicines must be intermitted, rest enjoined, and, if necessary, dilute sulphuric acid, gallic acid, etc., administered, in order to moderate any inordinate flow. At the menstrual periods, there is a tendency to an inter-current attack of acute inflammation springing up; and this may extend so far as to render it requisite to apply leeches to the vulva, and to use the bran poultices, before the profuse flow can be arrested. After a menstrual period of the usual duration, the application of a few leeches, and the employment of the poultices for an 
hour or two, is beneficial, by reducing the fulness of the vessels, and relieving the increased inflammation which attends the recurrence of this function. But, as might be supposed, it is in this chronic stage of the inflammatory action, that vaginal lotions are of 80 much benefit. It cannot be necessary to particularise the various lotions which are useful, or the way in which these require to be modified, in order to suit the requirements of each individual case. It is sufficient to bear in mind that the milder forms ought to be first employed, as the acetate of lead, or even cold water, at the time of taking a hip-bath; while those of more stimulating qualities, as the sulphate or chloride of zinc, nitrate of silver, etc., are cautiously proceeded to. The necessity there is for the patient to lie on the back, with the hips raised, in order to use vaginal lotions efficiently, constitutes a great objection to them by many females, and in others, causes them to be used without this precaution, and consequently with little or no benefit. With proper attention of the female, it might be said that the speculum is never required in the treatment of this stage of these affections, and that lotions are always sufficient for their cure. But it is not always that patients will be so careful as to ensure the lotion passing to the upper part of the vagina, where the disease may become located; and in occasional cases of this kind, a strong solution of nitrate of silver, or the solid nitrate, lightly. passed over the surface of the membrane, through the means of the speculum, will remove, as if by a charm, after two or three applications, a troublesome discharge, and wandering pains which had existed for months previously.

Chronic inflammation of the vagina is a frequent attendant on affections of the uterus itself, and, I am also obliged to say, has frequently been mistaken for disease of this organ. It is chiefly from this cause, that so many contradictory opinions have been given as to the value of lotions in these affections: for. instance, in inflammation of the vagina, they will afford marked relief, and generally cure the disease; in inflammation of the vagina, attended with an affection of the uterus; they will be of much benefit by relieving one portion of the affection; but in a disease of the uterus itself, no good will be obtained from the employment of them. It is consonant with d-priori reasoning, to suppose that a local application, which only occasionally touches the uterus, and when it does touch, only washes the lips of the organ, could exert no beneficial influence on its diseases; and experience has fully shown this reasoning to be correct.

In respect to the treatment of that stage of these affections, wherein the tissues become thickened and altered, I have little to say. Here, all general medication, with the object of influencing the local disease, is apparently useless; yet as the general health has suffered, to a greater or less extent, from the lengthened continuance of the disease, and in various ways, remedies calculated to remove the constitutional derangement, present in each individual case, are not only of great benefit, but are essential to the cure. To reduce the thickening of the membrane itself, the stronger lotions, used with attention, are requisite, such as the chloride of zinc or of copper, the nitrate of silver, the tincture of iodine, etc. And the occasional application to the surface of the membranc, by the aid of the speculum, of these substances, in 
stronger solution than they can be used as lotions, hastens the removal of the thickening of the tissues. Frequently the employment of one substance in strong solution, whilst using another as a vaginal lotion, is more beneficial than the employment of either of these substances alone.

9 1, Langham Place.

\section{ON DISEASE OF THE INTERNAL EAR; \\ EXTENDING THROUGH THE MEDIUM OF THE AUDITORY NERVE, TO THE MEDULLA OBLONGATA AND BASE OF THE BRAIN.}

By JOSEPH TOYNBEE, Esq., F.R.S., F.R.C.S., Aural Surgeon to St. Mary's Hospital; Consulting Aural Surgeon to the Asylum for the Deaf and

Dumb; and Consulting Surgeon to the St. George's and St. James's General Dispensary, London.

Ir has been shewn by numerous observers, that diseases of the ear are not unfrequently the source of mischief to the brain or its mem. branes. In a paper published in the thirty-fourth volume of the Medico-Chirurgical Transactions, I have attempted to show that there are three ways whereby disease is propagated from the ear to the brain, namely,-

1. From the external meatus and mastoid cells to the lateral sinus and cerebellum.

2. From the tympanic cavity to the cerebrum.

3. From the labyrinth to the medulla oblongata and base of the brain.

In the present communication, I purpose treating of the third class of cases only.

It is very rare to find disease originating in the labyrinth, it being generally communicated to that cavity from the tympanum. One of the most common affections of the ear is catarrhal inflammation of the mucous membrane lining the tympanum, a disease which has hitherto been included under the term otorrhœa; this affection of the tympanum does not, however, frequently terminate in ulceration, and therefore it is a case of comparative rarity to find the attachments of the stapes to the fenestra ovalis destroyed, and this bone entirely disconnected or discharged from the ear. That the latter result does, however, sometimes occur, is shown by the discharge of the ossicle during life, and by the existence of some of the cases to which I am about to draw attention. The stapes being once removed, there is a communication between the tympanic cavity and that of the vestibule, and the disease of the tympanum is liable to extend inwards. When this is the case, the membranous labyrinth is destroyed by suppuration, and the auditory nerve becomes involved in the disease. Sometimes the substance of the nerve is wholly destroyed along its whole length, at others it is simply inflamed and thickened; but whichever of these changes occurs, the disease from the labyrinth is prolonged to the base 